\title{
Numerical Modelling and Experimental Validation of Twin-Screw Expanders
}

\author{
Kisorthman Vimalakanthan *, Matthew Read and Ahmed Kovacevic
}

School of Mathematics, Computer Science and Engineering, Department of Mechanical Engineering and Aeronautics, University of London, London EC1V 0HB, UK; m.read@city.ac.uk (M.R.); a.kovacevic@city.ac.uk (A.K.)

* Correspondence: k.vimalakanthan@city.ac.uk

Received: 6 August 2020; Accepted: 2 September 2020; Published: 9 September 2020

\begin{abstract}
Positive displacement machines have been identified as appropriate expanders for small-scale power generation systems such as Organic Rankine Cycles (ORCs). Screw expanders can operate with good efficiency in working fluids under both dry and two-phase conditions. Detailed understanding of the fluid expansion process is required to optimise the machine design and operation for specific applications, and accurate design tools are therefore essential. Using experimental data for air expansion, both CFD and chamber models have been applied to investigate the influence of port flow and leakage on the expansion process. Both models are shown to predict pressure variation and power output with good accuracy. The validated chamber model is then used to identify the optimal volume ratio and rotational speed for experimental conditions.
\end{abstract}

Keywords: twin screw; air; expander; performance; optimisation; chamber model; CFD; validation; built-in volume ratio

\section{Introduction}

There is currently significant interest in reducing global greenhouse gas emissions from industrial processes, which alone account for almost 26\% (275 Mtoe/yr) of Europe's energy consumption [1]. Studies looking at global thermal energy availability [2] have shown that about $52 \%$ of the primary energy consumption is currently being rejected as waste heat. Of this global waste heat potential, $63 \%$ exists as low-temperature $\left(<100^{\circ} \mathrm{C}\right)$ heat sources. Waste heat energy recovery systems seem to be an attractive proposition that can potentially reduce energy consumption and can help to decarbonise industrial processes.

The Organic Rankine Cycle (ORC) provides a means of extracting useful electrical or mechanical power from heat sources at low temperature levels. However, this power is extracted with much lower thermal efficiencies than conventional high-temperature Rankine cycles. Additionally, low-temperature ORC systems generally demand a larger heat exchange area per unit power generation, resulting in higher investment costs for heat transfer equipment, with considerable work input for the feed pump due to the lower latent heat of evaporation of the organic fluids compared to water. Conventional ORC cycles are usually limited to dry vapour admission to turbines, which leads to the complication of having to remove the superheat before condensation begins, with an associated increase in the surface area required for heat transfer.

The thermal efficiency of ORCs can generally be increased by allowing a higher mean temperature of heat addition (in accordance with Carnot's principle) or by reducing the mean temperature of heat rejection. By allowing expansion to take place within the two-phase region, the ORC system can achieve a higher mean temperature of heat addition to increase cycle efficiency and to avoid the requirement to desuperheat the working fluid before the condenser, thereby reducing the mean temperature of heat rejection [3]. Allowing two-phase conditions at the expander inlet also reduces the 
constraints due the heat exchanger minimum temperature difference, leading to better temperature matching of the heat source and working fluid. This offers the potential to increase heat recovery from the source fluid, thereby increasing the net power output.

The potential thermodynamic and economic benefits of ORC systems, including the trilateral flash cycle [4] and their optimisation [5] considering expansion of initially saturated liquid, are reported in the literature. Several studies have also looked at the working fluid selection [6] for working in subcritical and trans-critical ORC cycles [7] using screw expanders. There is, however, a lack of experimental validation for expander performance models used in these studies.

The expansion of two-phase, liquid vapour mixtures presents serious challenges for turbomachinery but can be achieved with good efficiency in positive displacement machines. A number of different types of volumetric expanders have been considered for use in small-scale ORC systems, as reviewed by Zywica et al. [8]. The general requirements for a high expansion ratio, a high isentropic efficiency and low cost mean that scroll, screw, rotary vane and reciprocating piston machines can be suitable depending on the necessary working fluid, flow rate and system pressure [9]. For power outputs in the tens of kWs, screw expanders have been identified as a suitable expander technology for low-temperature waste heat recovery applications. In these applications, expansion of the fluid from saturated liquid [10] or two-phase conditions [3] has been shown to allow maximum net power output from a given waste heat source. However, one of the main challenges with two-phase expansion is the large density change, which influences the physical size requirements for positive displacement machines such as screw expanders.

High efficiency can be achieved by matching the screw expander's built-in volume ratio, $\epsilon_{v}$, to the volumetric expansion of the fluid in the process; the maximum value of $\epsilon_{v}$ is however limited due to geometrical constraints of the screw rotors, increased filling losses due to the decreasing size of the inlet port and the decreasing mass flow rate for a given machine size. The influence of these different factors makes performance prediction and optimisation of screw expanders essential when considering their use in ORC systems. Thus, it is important to develop a validated model that accurately captures the effect of built-in volume ratio and operating conditions on the expander performance.

This paper will focus on the case of single-phase expansion of air using a twin-screw expander. The aim is to establish an accurate and reliable model for the expansion of air, while future work will focus on the more complex case of two-phase expansion, leading to a robust tool for general use in performance prediction of power systems. Two modelling approaches will be considered. Firstly, a quasi-1D modelling tool based on the "chamber model" approach [11] has been developed for twin-screw expanders. Secondly, 3D CFD modelling has also been performed for comparison. Previous studies by Kovacevic et al. have described the CFD grid generation and calculation methodology in detail [12] and demonstrated good agreement with measured data for screw expander applications [13]. The numerical results were computed for the expander with characteristics defined in Table 1 and Figure 1 running on single-phase air and compared against the experimental data presented by Hutker et. al. [14]. An extension of this work validating two-phase R245fa expansion is the focus of future research publications. For single- or two-phase conditions, the validated model allows for evaluation of maximum efficiency maps as a function of built-in volume ratios at different pressure ratios. This will be demonstrated for the air expander considered in this paper. These established performance maps can be used with cycle optimisation tools to evaluate the optimum design of twin-screw expander geometry and its operating conditions for specific applications within power generation systems. 
Table 1. Geometrical data of the GL51.2-M twin-screw expander.

\begin{tabular}{|c|c|c|}
\hline & Male Rotor & Female Rotor \\
\hline No of lobes & 3 & 5 \\
\hline Wrap angle & $200^{\circ}$ & $120^{\circ}$ \\
\hline Head diameter & $72 \mathrm{~mm}$ & $67.5 \mathrm{~mm}$ \\
\hline Length & \multicolumn{2}{|c|}{$101 \mathrm{~mm}$} \\
\hline Built-in volume ratio (Vi) & \multicolumn{2}{|c|}{1.47} \\
\hline Displaced volume per male rotor revolution & \multicolumn{2}{|c|}{$285 \mathrm{~cm}^{3}$} \\
\hline Rotor profile & \multicolumn{2}{|c|}{ mod. asym. SRM-profile } \\
\hline $\mathrm{HP} / \mathrm{LP}$ ports arrangements & \multicolumn{2}{|c|}{ Axial and Radial/Axial } \\
\hline $\begin{array}{c}\text { Design Clearance } \\
(\text { Interlobe } \times \text { Radial } \times \text { HP End } \times \text { LP End })\end{array}$ & \multicolumn{2}{|c|}{$50-80 \mu \mathrm{m} \times 80 \mu \mathrm{m} \times 100 \mu \mathrm{m} \times 250 \mu \mathrm{m}$} \\
\hline
\end{tabular}

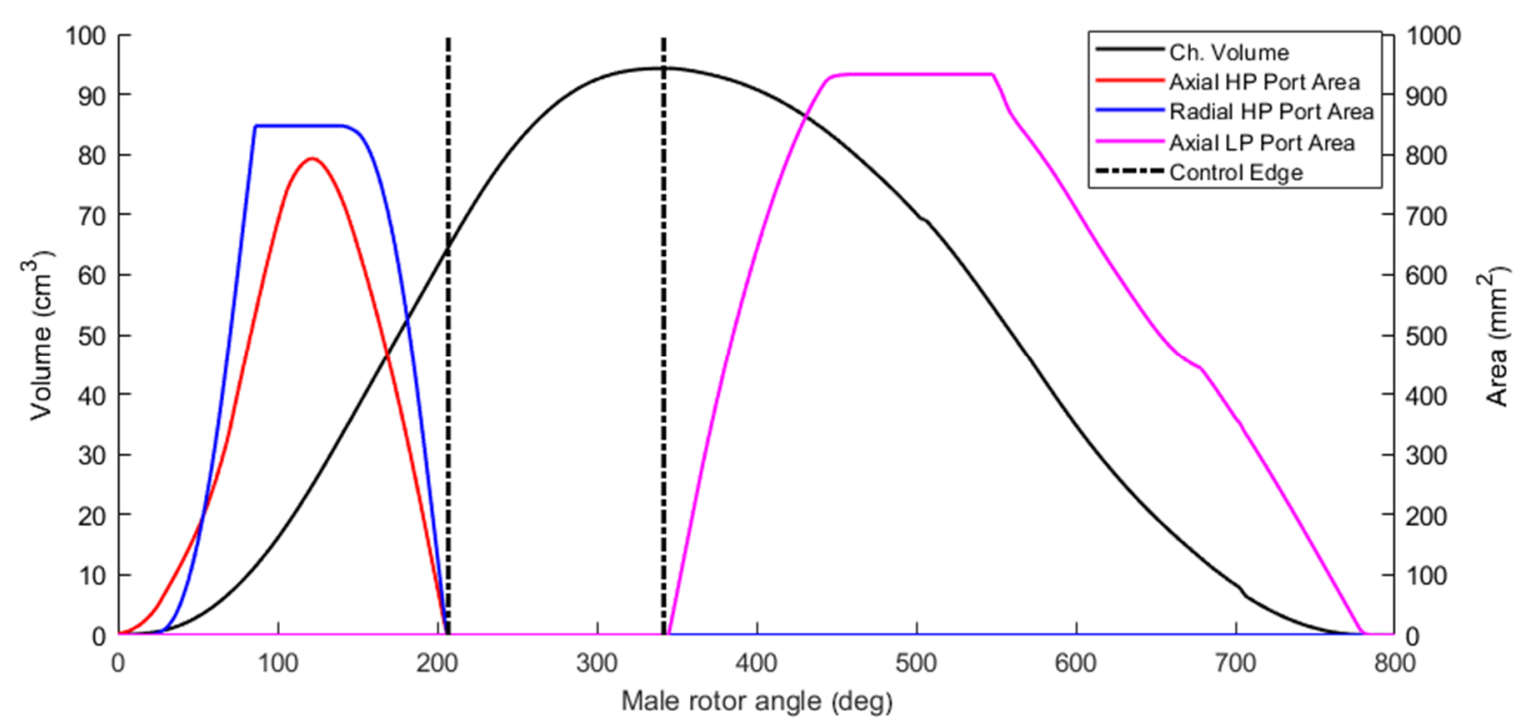

Figure 1. Port areas and volume curve of the screw expander GL51.2-M.

\section{Modelling}

Two numerical modelling approaches for twin-screw expanders are presented in this section. The first is a 1D chamber model (1D Ch. Model), which is a computationally efficient approach to solve the system of equations. The second approach considers the expander in its three-dimensional (3D CFD) numerical environment and models the full three-dimensional Navier-Stokes equations with RANS k-e closure for turbulence modelling, which requires several days of computation on high-performance clusters. The in-house computational code SCORGC [13] enables use of both chamber modelling and 3D CFD in screw machines.

\subsection{Chamber Model (1D Ch. Model)}

Based on the geometry calculation from SCORG V5.7 (Figure 1), the commercial software GT-SUITE [15] was used to implement the multi-chamber modelling approach outlined in [11]. This software models the working chamber of the expander and manifolds using chamber modelling, where scaler variables are assumed to be uniform within, while all other flow component are modelled using 1D formulation of the Navier-Stokes equations on a staggered grid spatial discretisation. 
The expander is divided into various fluid components (Figure 2) such that an inlet pipe connects to a flow-split that feeds the working chambers of the expander, which then allows the fluid to accumulate to another flow split and exit via outlet pipe work. The pipe volumes are divided into sub-volumes while the chamber and flow split manifolds are represented by a single volume, while the vector variables are solved at the boundary.

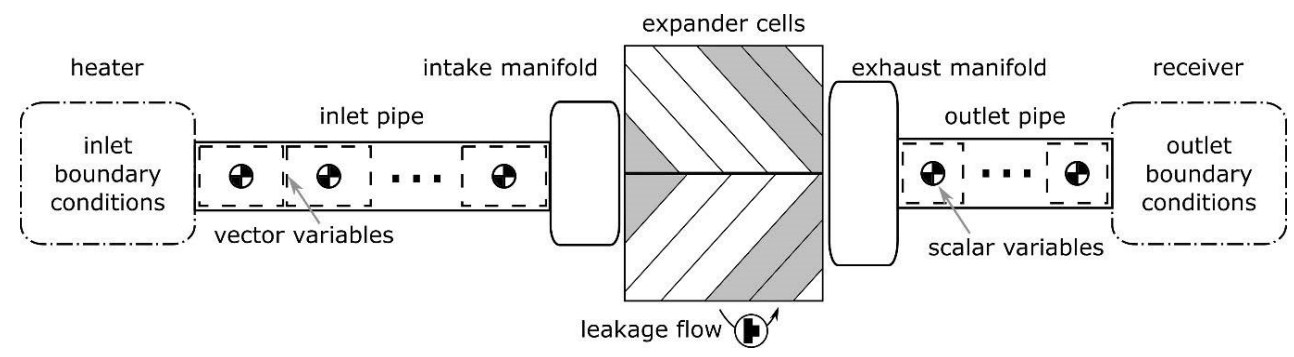

Figure 2. Modelling approach for the 1D chamber model (1D Ch. Model) [10].

The chamber volume and the corresponding flow areas for ports and leakage paths are provided as a function of rotor angle (Figure 1). Currently, no heat transfer is modelled and the walls of the components are modelled as adiabatic.

All fluid components within the 1D Ch. Model including leakage flows are modelled as flow through an orifice. For the validation case considering gaseous air, the orifice flow is modelled based on the isentropic nozzle relationships for subsonic and chocked flow regimes.

For the two-phase environment, the nozzle flow is modelled using incompressible Bernoulli equation for liquids, and the isentropic nozzle relationships are considered for gases. This requires the calculation of ratio of specify heat $(\gamma)$ and dynamic viscosity $(\mu)$, which are calculated as an equivalent property using a weighted average based on the fluid quality $(\chi)$ as shown in Equations (1) and (2).

$$
\begin{gathered}
\gamma_{\text {eqv }}=\gamma_{\text {vap }} \chi+\gamma_{\text {liq }}(1-\chi) \\
1 / \mu_{\text {eqv }}=\chi / \mu_{\text {vap }}+(1-\chi) / \mu_{\text {liq }}
\end{gathered}
$$

The systems of conservation equations are solved using explicit 5 th-order Runge-Kutta integration scheme to solve for mass and internal energy. With the known volume and mass, the corresponding density is calculated. The density and internal energy values are used to then determine the pressure and temperature via the NIST REFPROP database [16].

The GT-SUITE model implementation of the twin-screw GL51.2-M expander is shown in Figure 3. The 3/5 lobed machine is modelled with 9 chambers in total, which is calculated based on the maximum number of working chambers that the meshing rotors can form at a point in time. All chambers are connected to the inlet and outlet manifolds, and dedicated links are modelled for axial and radial ports, respectively. The leakage paths are also modelled via their own dedicated connections between the chambers, and it is connected via a cyclic link where the last chamber is connected to the first chamber in order to allow continuity and leakage access to all possible paths.

The explicit solver was set to consider a maximum time step corresponding to $1^{\circ}$, solving the equation for the full cycle $\left(360^{\circ}\right)$. The convergence criteria set at steady-state condition on mass flow rate and pressure, i.e., $0.2 \%$ variation on mass flow rate and pressure in flow connections compared with the results from the previous cycle. 


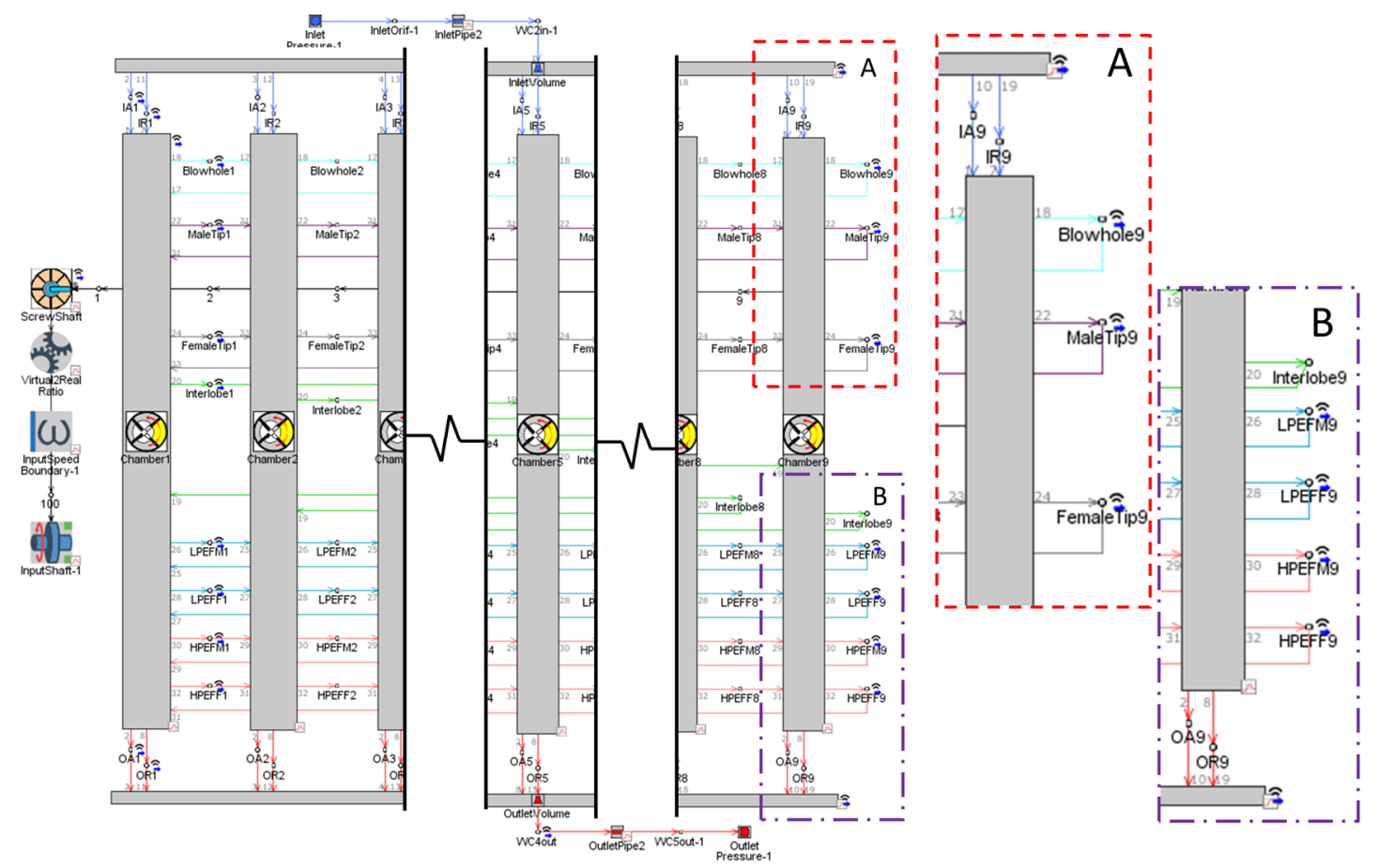

Figure 3. GT-SUITE model of GL51-M Expander; IA = inlet axial port, IR= inlet radial port, OA = outlet axial port, $\mathrm{OR}=$ outlet radial port, Male Tip = male rotor tip clearance leakage, Female Tip = female rotor tip clearance leakage, LPEFM = low-pressure end face male rotor leakage, LPEFF = low-pressure end face female rotor leakage, HPEFM = high-pressure end face male rotor leakage and HPEFF = high-pressure end face female rotor leakage.

\subsection{Computational Fluid Dynamics Model (3D CFD)}

To assess the quality of the 1D Ch. Model discussed in the previous section, 3D CFD simulations were conducted and compared against the experimental data. As the working fluid flows through the machine, the net force exerted by the fluid on the rotors causes rotation, with expansion of the fluid occurring once the inlet port closes (Figure 4). This results in net power output via the shaft of the male rotor, which can be used to drive a mechanical load or electrical generator.

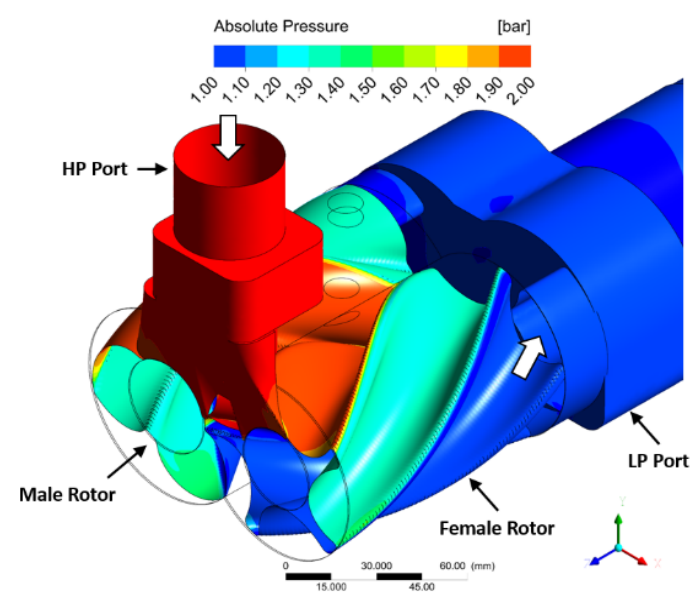

Figure 4. Pressure variation in twin-screw expander.

The computational fluid domain is decomposed into three main regions (Figure 5), namely the high-pressure (HP) port, rotor domain (containing the male and female rotors) and the low-pressure 
(LP) port. Moreover, the end face clearances were modelled with additional domains attached on both sides of the rotor, i.e., the HP end face leakage was modelled with an additional domain discretising the space between the HP port and rotor. A numerical (GGI) interface was used to connect all computational domains. The rotor domain is updated with a corresponding grid at each time intervals to model the rotation.
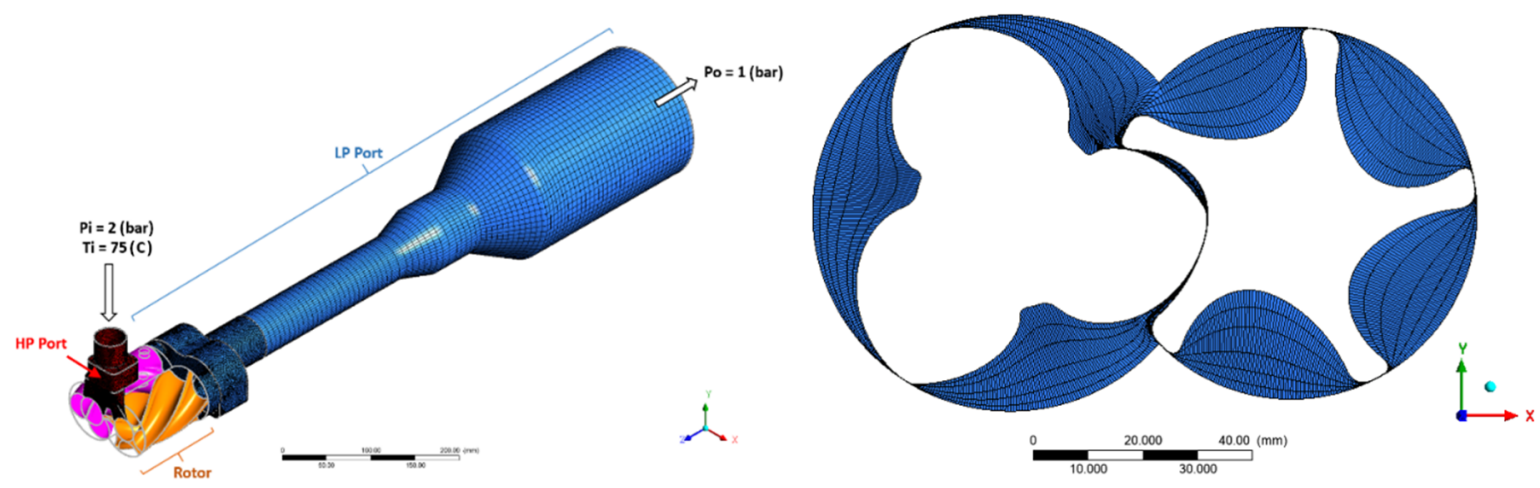

Figure 5. CFD domains with surface mesh for the GL51.2-M twin-screw expander.

The convergence criteria for mass, momentum and energy equations were set to r.m.s values of 1E-4, 1E-3 and 1E-3, respectively. Surplus amounts of time steps were considered for all simulations until a cyclic repetition was observed for pressure, power and mass flow rate via the machine.

\section{Results}

Numerical simulations were conducted to replicate the experimental conditions reported in [14]. A range of inlet pressures between 1.5-3 bar was investigated at an inlet temperature of $75^{\circ} \mathrm{C}$, with the expander rotational speed ranging from 1000-16,000 RPM.

The design clearance gaps for the GL51-2M expander were defined as 50-80 $\mu \mathrm{m}$ for the interlobe, $80 \mu \mathrm{m}$ radial and 100 and $250 \mu \mathrm{m}$ for the high-pressure (HP) and low-pressure (LP) end faces, respectively. However, due to mechanical and thermal loads, these clearance gaps are known to change in operation. Operational clearance settings of $10 \times 80 \times 640 \times 10 \mu \mathrm{m}$ corresponding to the interlobe, radial, HP end face and LP end face were chosen for both numerical simulations. This clearance setting was evaluated based on a genetic optimisation routine that minimises the differences between the computed and measured power and mass flow values while closely matching the measured internal pressure curve at 2 bar inlet pressure with 4000 RPM rotational speed.

\subsection{Validation Results}

The results from both 3D CFD and 1D chamber models agree well with the measured indicated power (Figure 6 and Table 2) at lower rotational speeds.

The predicted power values from the chamber model are within $2 \%$ of the measurements $(<8000$ RPM). However, the overall results (Figure 6) clearly show that the accuracy of the numerical simulations deteriorates with increasing rotational speeds, specifically beyond 10,000 RPM.

The 3D CFD model consistently underpredicts the power output and overpredicts the mass flow rates for both simulated rotational speeds, while the chamber model predicts slightly larger power output and mass flow rates. Details of the validation study comparing the internal pressure traces are presented in Figures 7 and 8 for the two rotational speeds shown in Table 2, which is discussed in the following section. 


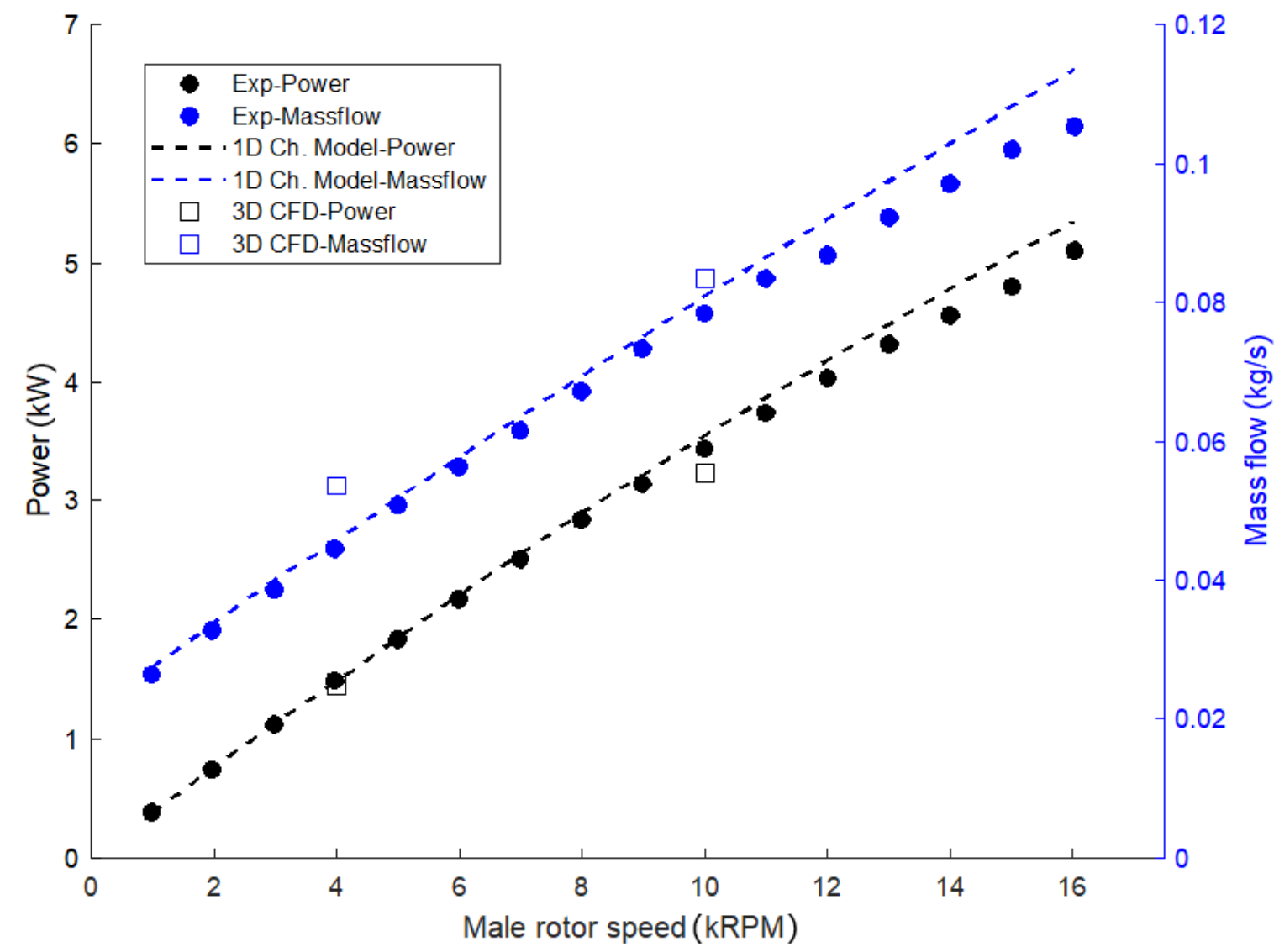

Figure 6. Measured and calculated indicated power and mass flow as a function of rotational speed $\left(\mathrm{Pi}=2\right.$ bar and $\left.\mathrm{Ti}=75^{\circ} \mathrm{C}\right)$.

Table 2. Indicated power and mass flow rates for 4000 and 10,000 RPM.

\begin{tabular}{ccccc}
\hline & \multicolumn{2}{c}{$\mathbf{n = 4 0 0 0}$ RPM } & \multicolumn{2}{c}{$\mathbf{n = 1 0 , 0 0 0 ~ R P M ~}$} \\
\hline & Power (kW) & Mass Flow $(\mathbf{k g} / \mathbf{s})$ & Power $(\mathbf{k W})$ & Mass Flow $(\mathbf{k g} / \mathbf{s})$ \\
\hline Exp & 1.464 & 0.0450 & 3.445 & 0.0790 \\
1D Ch. & 1.477 & 0.0456 & 3.552 & 0.0809 \\
$\begin{array}{c}\text { Model } \\
\text { 3D CFD } \\
\text { Model }\end{array}$ & 1.442 & 0.0536 & 3.239 & 0.0834 \\
\hline
\end{tabular}

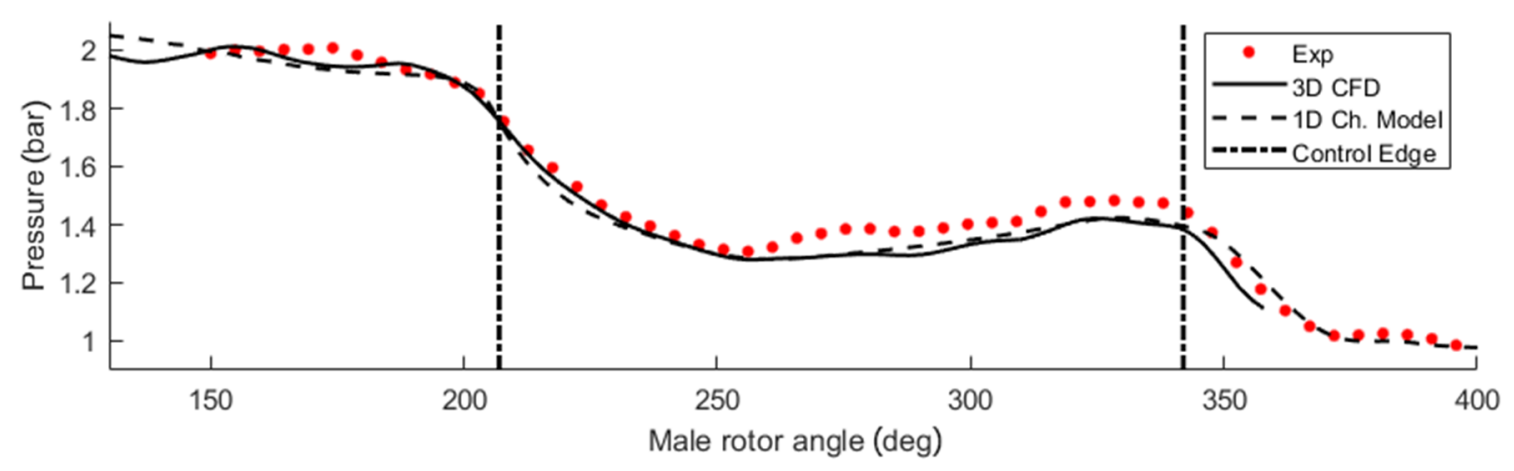

Figure 7. Validation of simulated pressure curves against male rotor's rotational angle ( $\mathrm{n}=4000 \mathrm{RPM}$, $\mathrm{Pi}=2$ bar and $\left.\mathrm{Ti}=75^{\circ} \mathrm{C}\right)$. 


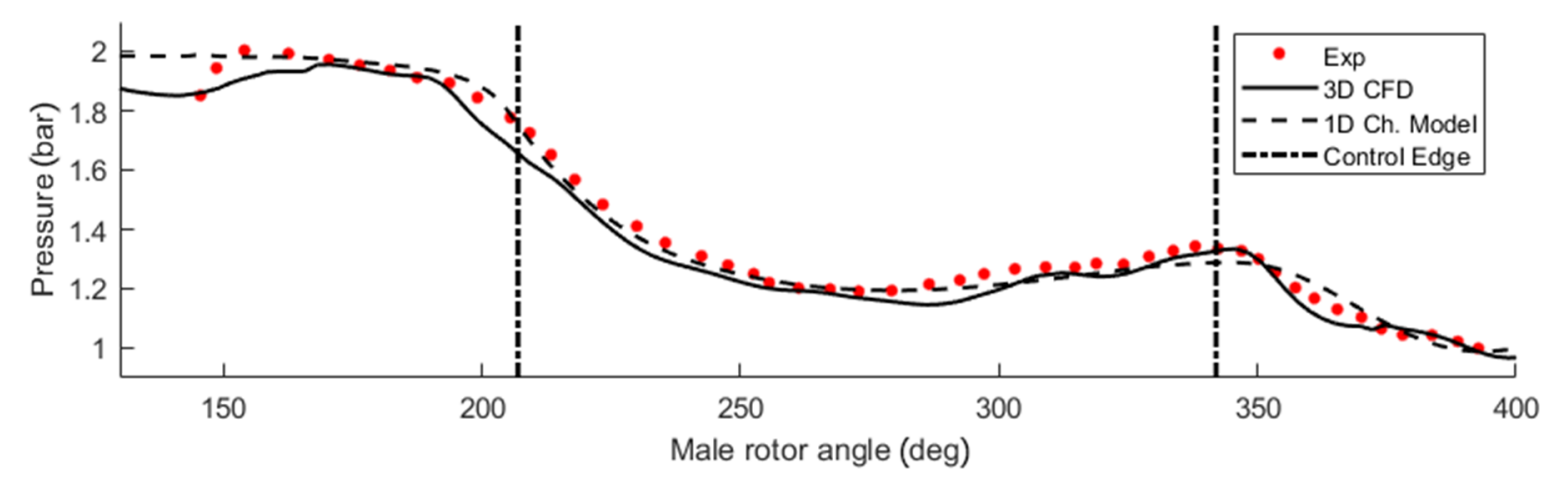

Figure 8. Validation of simulated pressure curves against male rotor's rotational angle ( $\mathrm{n}=10,000 \mathrm{RPM}$, $\mathrm{Pi}=2$ bar and $\mathrm{Ti}=75^{\circ} \mathrm{C}$ ).

At 4000 RPM, the CFD model significantly overpredicts the mass flow rates by $19 \%$ and underpredicts the power output by $1.5 \%$, which results in a substantial underprediction of the expander's specific power output $(17 \%)$. The specific power output of an expander is a measure of its isentropic and mechanical efficiency, and the chamber model accurately computes the specific power within $1 \%$ of the measurements. At a larger rotational speed of 10,000 RPM, the CFD results show better prediction of the mass flow rate and the difference with measurement reduces to $6 \%$.

The validation study is conducted using the internal pressure measurements for different rotational speeds: 4000 (Figure 7) and 10,000 RPM (Figure 8), for the inlet pressure of 2 bar. The results show that both numerical models compute the indicated pressures with reasonable accuracy. The filling (up to $208^{\circ}$ ) and refilling (caused by net leakage of fluid into the working chamber between 250-380 trends seen from the measurements are captured well with both numerical models.

Negligible differences are found between the chamber and high-fidelity 3D CFD models at 4000 RPM. At a higher rotational speed of 10,000 RPM, the low fidelity chamber model utilizing simple orifice equations shows better prediction for the filling losses than the CFD results at 2 bar inlet pressure.

Comparing the indicated diagrams for different inlet pressures at a rotational speed of 10,000 RPM (Figure 9) reveals that the chamber model consistently underpredicts filling losses with increasing inlet pressures (or density). A $6 \%$ difference in filling pressure is found between the chamber model predictions and measurement, at the highest inlet pressure of 3 bar. However, the results also show that refiling losses are accurately predicted with the chamber model. This suggests that, despite modelling the leakages with reasonable accuracy, the orifice assumption based on isentropic nozzle relationship is insufficient to accurately capture the losses incurred via the high-pressure port, especially at the large pressure ratios (3:1).

Based on the postprocessed results, it was clear that the two numerical models calculate significantly different flow characteristics from each other (Figure 10). The CFD model simulating the actual three-dimensional port geometry $\left(16^{\circ}\right.$ flow angle) calculates much larger flow via the radial port than the axial one, while the chamber model with orifice assumption $\left(90^{\circ}\right)$ shows similar proportion of the flow via both ports until $150^{\circ}$ of the male rotor position, where flow through the radial port dominates.

These results stress the need for an improved model for the high-pressure port. One possibility is to account for a restricted flow via the axial port based on skewed geometry, such as using a reduced port area profile based on the components of the flow directions. Improving the flow characteristics based on the 3D port geometry is likely to achieve higher accuracy using the chamber model approach. 


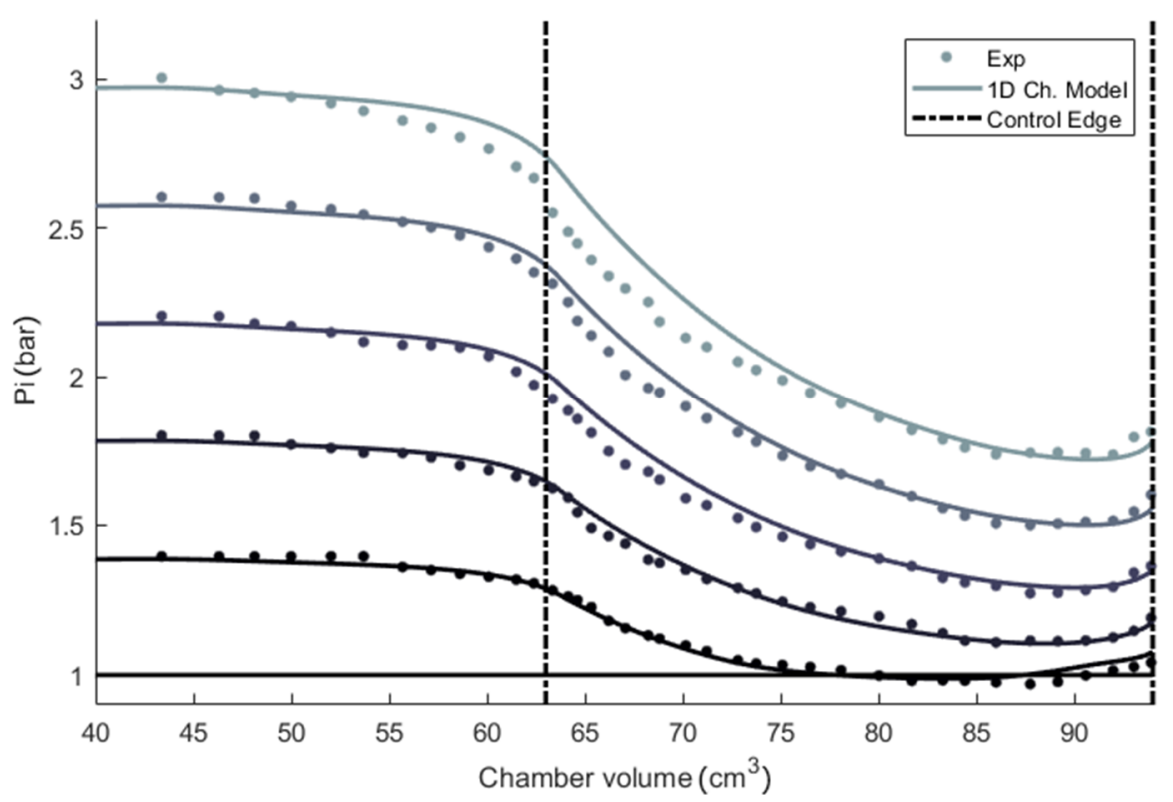

Figure 9. Validation of simulated indicated diagrams for different inlet pressure $(n=10,000 \mathrm{RPM}$ and $\left.\mathrm{Ti}=75^{\circ} \mathrm{C}\right)$.
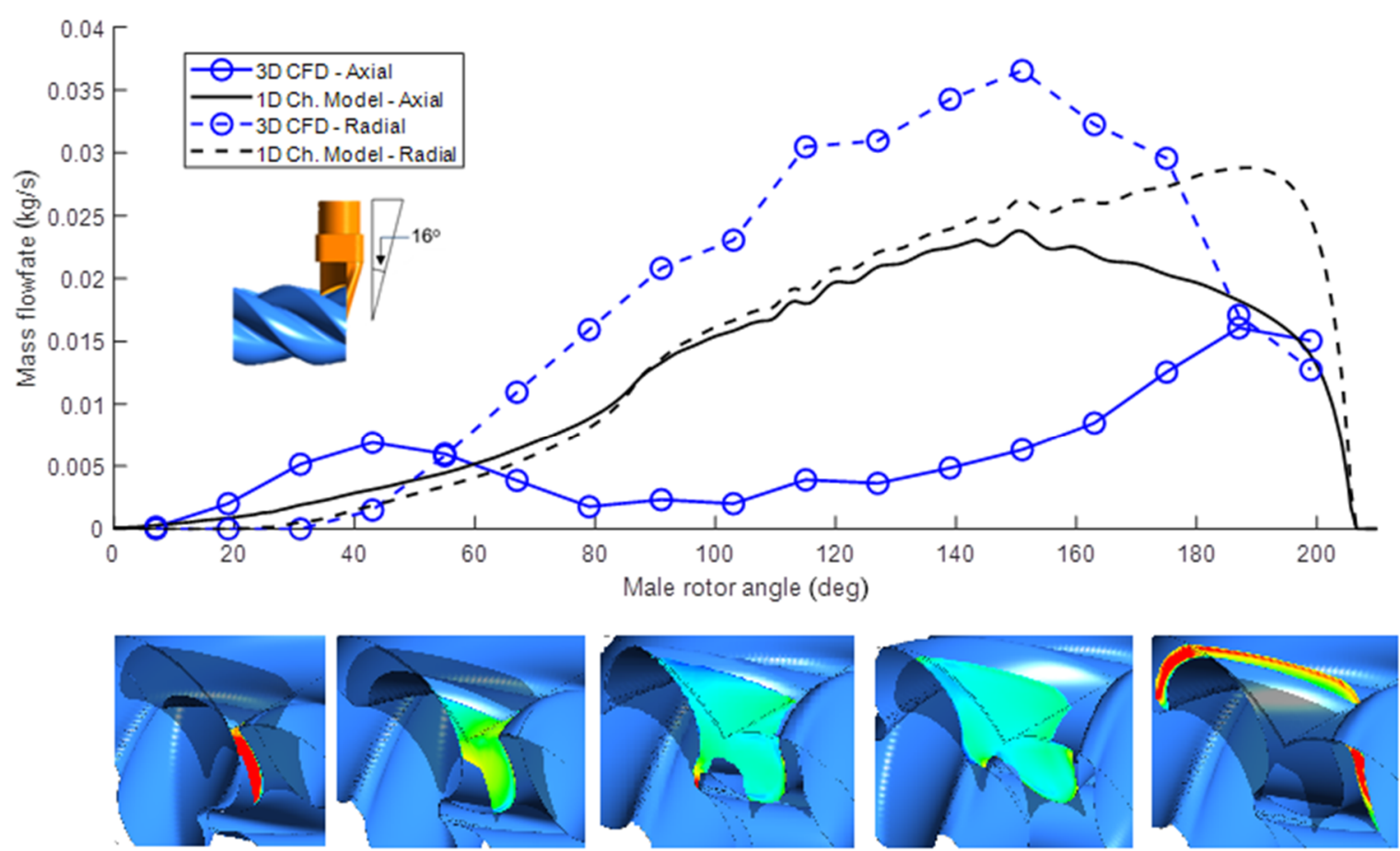

Figure 10. High-pressure flow characteristics for the GL51.2-M twin-screw expander ( $\mathrm{Pi}=2 \mathrm{bar}$ and $\mathrm{n}=4000 \mathrm{RPM})$.

\subsection{Maximum Efficiency Maps}

The isentropic efficiency of a twin-screw expanders depends on the built-in volume ratio $\left(\epsilon_{v}\right)$, the actual volumetric expansion ratio of the fluid and the rotational speed. The built-in volume ratio is a function of the high-pressure port geometry, while the volumetric expansion ratio is based on the inlet and outlet fluid conditions. These two parameters determine the expanders' ability to match the expansion occurring within the machine to the required application. At higher rotational speeds, 
the leakage become a lower proportion of the mass flow rate, resulting in higher maximum isentropic efficiency when operating with a suitable value of $\epsilon_{v}$. Increasing rotational speed tends to increase the pressure drop during filling of the working chambers; this pre-expansion of the fluid can lead to optimum values of $\epsilon_{v}$ well below the volumetric expansion ratio for the process. Accurate modelling is therefore necessary when assessing system performance and optimum expander design.

Using the established chamber model, the maximum isentropic efficiency map was evaluated using the steps below for this expander running on air:

1. Inlet pressure, $P_{i}$, is fixed.

2. $\quad \dot{m}$ and $\eta$ are calculated for the range of $\omega$ and $\epsilon_{v}$ values.

3. Maximum values of $\eta$ (and corresponding values of $\omega$ and $\epsilon_{v}$ ) are identified as a function of $\dot{m}$.

4. Repeat steps $1-3$ across the range of $P_{i}$ values.

5. Calculated data allows contour plots of maximum $\eta$ and corresponding $\epsilon_{v}$ and $\omega$ values to be functions of $P_{i}$ and $\dot{m}$.

The range of values considered for the input parameters was $1 \leq \epsilon_{v} \leq 10$ in steps of 0.5 , $500 \leq \omega \leq 16,000$ RPM in steps of 500 RPM and $1.5 \leq P_{i} \leq 3$ bar in steps of 0.25 bar. A constant outlet pressure of 1 bar was used in all cases. The resulting contour maps are shown in Figures 11-13.

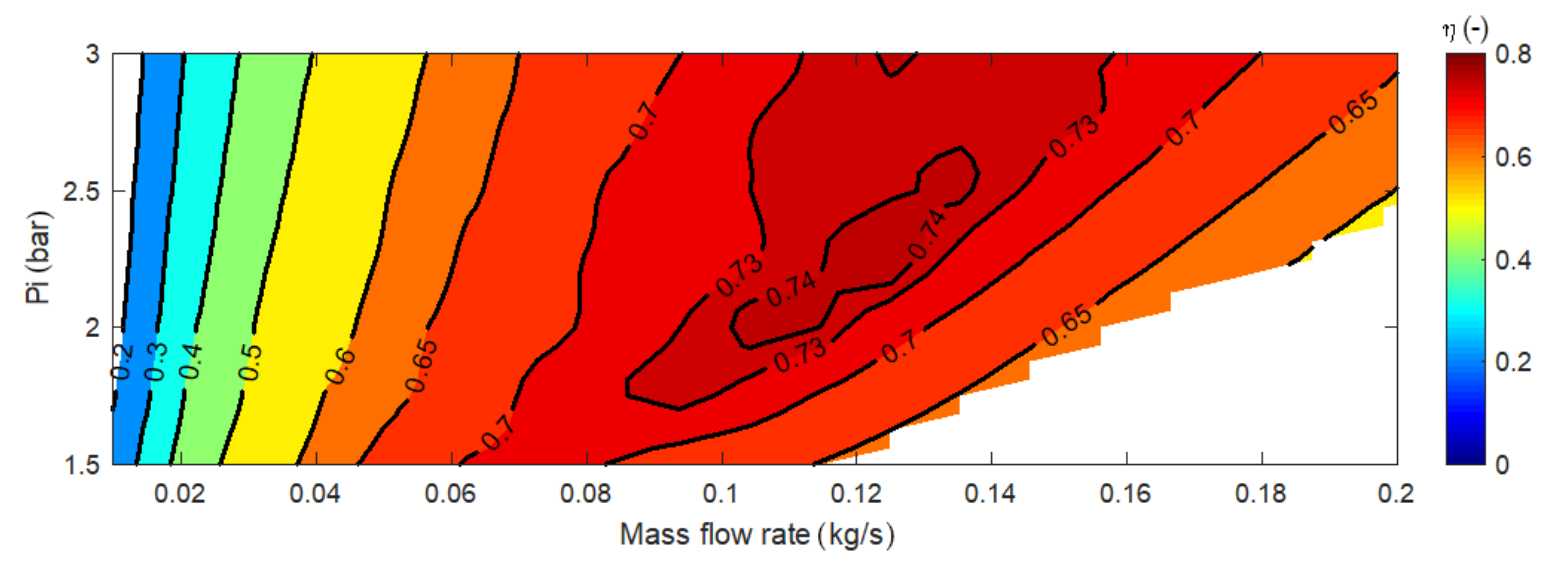

Figure 11. Maximum efficiency map for GL51 twin-screw expander running on air $\left(\mathrm{Ti}=75^{\circ} \mathrm{C}\right.$ and Po $=1$ bar).

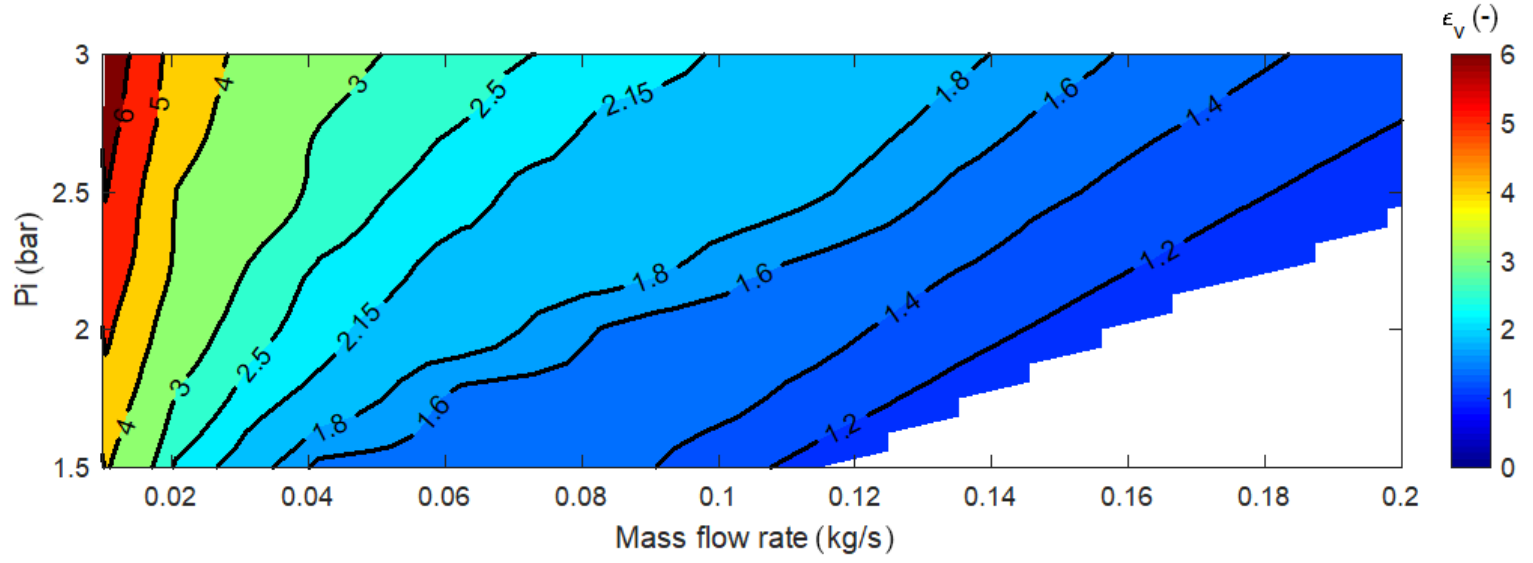

Figure 12. Built-in volume ratio $\left(\epsilon_{v}\right)$ corresponding to maximum isentropic efficiency of GL51 twin-screw expander running on air $\left(\mathrm{Ti}=75^{\circ} \mathrm{C}\right.$ and $\left.\mathrm{Po}=1 \mathrm{bar}\right)$. 


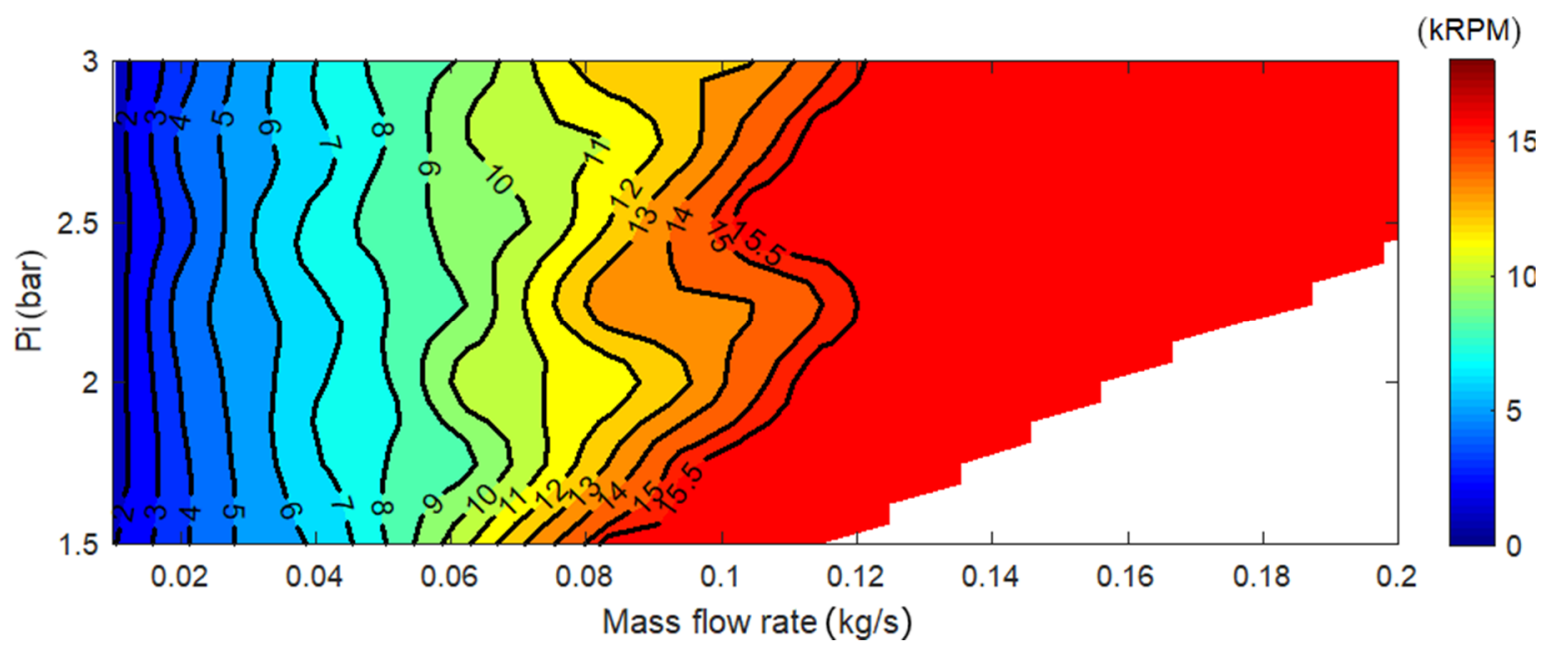

Figure 13. Rotational speeds corresponding to maximum isentropic efficiency of GL51 twin-screw expander running on air $\left(\mathrm{Ti}=75^{\circ} \mathrm{C}\right.$ and $\left.\mathrm{Po}=1 \mathrm{bar}\right)$.

Based on the results (Figure 11), a better efficiency operation is achieved with increasing mass flow rates up to $0.07 \mathrm{~kg} / \mathrm{s}$ for all investigated inlet pressures. The global optimum efficiency is achieved at mass flow rates between $0.100-0.140 \mathrm{~kg} / \mathrm{s}$ with inlet pressures of $2.1-2.6 \mathrm{bar}$, respectively. This range of operation with maximum efficiency is achieved with a close to constant volume ratio of $\epsilon_{v}=1.6$ (Figure 12) for rotational speeds above 15,500 RPM (Figure 13). Larger mass flow rates beyond $0.14 \mathrm{~kg} / \mathrm{s}$ show reductions in maximum efficiency. The losses during filling mean that the pressure at the start of expansion is relatively low, which effectively reduces the work done (area of the $\mathrm{pV}$ diagram), resulting in less mass per cycle and less work per cycle. The pressure drop across the inlet port means that there is lost work, and so, specific work tends to decrease at higher speeds.

For the conditions above 15,000 RPM, the experimented machine configuration with $\epsilon_{v} 1.47$ was found to be operating close to the best conditions suggested by the maximum efficiency maps. At the experimented condition with inlet pressure of 2 bar and mass flow rate of $0.102 \mathrm{~kg} / \mathrm{s}$, the experimentally established isentropic efficiency was found to be 0.7 , while the optimum operation recommended by the efficiency map (Figure 11) for 2 bar inlet pressure with $0.102 \mathrm{~kg} / \mathrm{s}$ is with $\epsilon_{v}=1.49$, where the machine achieves an isentropic efficiency of 0.74 .

\section{Conclusions}

Positive displacement machines have been identified as appropriate expanders for small-scale power generation systems such as ORCs. Detailed understanding of the fluid expansion process is required to optimise the machine design and operation for specific applications, and accurate design tools are therefore essential.

Using experimental data for air expansion, both CFD and chamber models have been applied to investigate the numerical accuracy on the power output and mass flow rate. A detailed validation study was conducted using the measured internal pressure curves to assess the leakage and the filling loss predictions. Both models are shown to predict pressure variation and power output with good accuracy. However, the results also indicate that the accuracy of the numerical predictions deteriorates with increasing rotational speeds and increasing inlet densities. These finding suggest that further investigations are required to quantify and assess the simple orifice assumption considered for leakage and filling loss predictions. Nevertheless, the validated chamber model has been successfully used to demonstrate the process of determining the optimum built-in volume ratio and rotational speed for the experimented conditions.

An extension of this work validating two-phase R245fa expansion is published at the Rankine 2020 conference [17]. 
Author Contributions: Conceptualization, K.V., M.R. and A.K.; methodology, K.V. and M.R.; validation, K.V.; formal analysis, K.V.; investigation, K.V.; resources, A.K.; data curation, K.V.; writing —original draft preparation, K.V.; writing-review and editing, K.V., M.R. and A.K.; visualization, K.V.; supervision, M.R. and A.K. All authors have read and agreed to the published version of the manuscript.

Funding: This research was funded by EPSRC (grant number: EP/P009131/1).

Acknowledgments: Authors would like to thank Andreas Brummer and Technical University of Dortmund for providing geometry and experimental results of GL-51 expander.

Conflicts of Interest: The authors declare no conflict of interest.

\section{Abbreviations}

The following abbreviations are used in this manuscript:

Exp Experimental

1D Ch. Model One-dimensional chamber model

3D CFD Model Three-dimensional computational fluid dynamics model

\section{References}

1. Panayiotou, G.P.; Bianchi, G.; Georgiou, G.; Aresti, L.; Argyrou, M.; Agathokleous, R.; Tsamos, K.M.; Tassou, S.A.; Florides, G.; Kalogirou, S.; et al. Preliminary Assessment of Waste Heat Potential in Major European Industries. Energy Procedia 2017, 123, 335-345. [CrossRef]

2. Forman, C.; Muritala, I.K.; Pardemann, R.; Meyer, B. Estimating the Global Waste Heat Potential. Renew. Sustain. Energy Rev. 2016, 57, 1568-1579. [CrossRef]

3. Read, M.; Smith, I.; Stosic, N.; Kovacevic, A. Comparison of Organic Rankine Cycle Systems under Varying Conditions Using Turbine and Twin-Screw Expanders. Energies 2016, 9, 614. [CrossRef]

4. Fischer, J. Comparison of Trilateral Cycles and Organic Rankine Cycles. Energy 2011, 36, 6208-6219. [CrossRef]

5. Read, M.; Smith, I.; Stosic, N. Optimisation of Power Generation Cycles Using Saturated Liquid Expansion to Maximise Heat Recovery. Proc. Inst. Mech. Eng. Part E 2017, 23, 57-69. [CrossRef]

6. Kolasinski, P. The Method of the Working Fluid Selection for Organic Rankine Cycle (ORC) Systems Employing Volumetric Expanders. Energies 2020, 13, 573.

7. Zhang, X.; Zhang, Y.; Cao, M.; Wang, J.; Wu, Y.; Ma, C. Working Fluid Selection for Organic Rankine Cycle Using Single-Screw Expander. Energies 2019, 12, 3197. [CrossRef]

8. Zywica, G.; Kaczmarczyk, T.Z.; Ihnatowicz, E. A Review of Expanders for Power Generation in Small-Scale Organic Rankine Cycle Systems: Performance and Operational Aspects. Proc. Inst. Mech. Eng. Part A 2016, 230, 669-684. [CrossRef]

9. Bao, J.; Zhao, L. A Review of Working Fluid and Expander Selections for Organic Rankine Cycle. Renew. Sustain. Energy Rev. 2013, 24, 325-342. [CrossRef]

10. Bianchi, G.; Kennedy, S.; Zaher, O.; Tassou, S.A.; Miller, J.; Jouhara, H. Numerical Modeling of a Two-Phase Twin-Screw Expander for Trilateral Flash Cycle Applications. Int. J. Refrig. 2018, 88, 248-259. [CrossRef]

11. Stosic, N.; Smith, I.K.; Kovacevic, A. Calculation of Screw Compressor Performance. Screw Compressors: Mathematical Modelling and Performance Calculation; Springer: Berlin/Heidelberg, Germany, 2005; pp. 49-75.

12. Kovacevic, A.; Rane, S. Algebraic Generation of Single Domain Computational Grid for Twin Screw Machines Part II-Validation. Adv. Eng. Softw. 2017, 109, 31-43. [CrossRef]

13. Rane, S.; Kovačević, A.; Stošić, N. Grid Generation for CFD Analysis and Design of a Variety of Twin Screw Machines. Designs 2019, 3, 30. [CrossRef]

14. Hütker, J.; Brümmer, A. Physics of a Dry Running Unsynchronized Twin Screw Expander. In Proceedings of the 8th International Conference on Compressors and their Systems, London, UK, 9-10 September 2013; pp. 9-10.

15. Manual, G.P.U. GT-SuiteTM Version 2019. Gamma Technologies. Available online: https://www.gtisoft.com/ download/general-download/ (accessed on 6 September 2020). 
16. Lemmon, E.; Huber, M.; McLinden, M. NIST Standard Reference Database 23, Reference Fluid Thermodynamic and Transport Properties (REFPROP), version 9.0, National Institute of Standards and Technology. Natl. Std. Ref. Data Ser. 2010, 22, 2010.

17. Vimalakanthan, K.; Read, M.; Kovacevic, A. Performance Prediction and Optimisation of Twin-Screw Expander. In Proceedings of the IIR International Rankine 2020 Conference-Heating, Cooling and Power Generation, Online Event, 27-30 July 2020. 